(c) 2010 IEEE. Personal use of this material is permitted. Permission from IEEE must be obtained for all other uses, in any current or future media, including reprinting/republishing this material for advertising or promotional purposes, creating new collective works, for resale or redistribution to servers or lists, or reuse of any copyrighted component of this work in other works. 


\title{
The Nodal Market Power Index (NMP Index) for Modelling and Visualising Market Power
}

\author{
M. R. Hesamzadeh, Graduate Student Member, IEEE, D. R. Biggar, Australian Energy Regulator, \\ $A E R$, and Australian Competition and Consumer Commission, ACCC, N. Hosseinzadeh, Member \\ IEEE, and P. J. Wolfs, Senior Member, IEEE
}

\begin{abstract}
This paper deals with a systematic way for modelling and visualising market power in liberalised electricity markets.

The paper first introduces a new index termed the "Nodal Market Power" index, the NMP index. The NMP index is calculated based on the concept of "social welfare" in economics and the game theory in applied mathematics. The oligopoly electricity market is modelled through a non-cooperative game and the solution concept of the Nash equilibrium. The solution concept of Nash equilibrium is reformulated as an optimisation problem. To tackle the multiple Nash equilibria problem, the worst Nash equilibrium in terms of the social cost to the society is selected. Then after, the NMP index is calculated for each node of power system. A colour contour map is used for visualising the market power using the NMP index.
\end{abstract}

Index Terms-Market Power, Stackelberg-Worst Nash Equilibrium, Nodal Market Power Index

\section{INTRODUCTION}

$\mathrm{M}$ ARKET power of a producer is the ability to profitably maintain market prices above competitive levels for a significant period of time, [1]. In economics, for a firm to have market power, two elements must be present:

- First, the firm must have the ability to influence the market price by varying its own output; and

- Second, in doing so, the firm must be able to earn excess returns in the medium or long-term, [2].

A firm which has no influence over the market price is said to be a price taker and is not deemed to have market power.

The exercise of market power in electricity market involves reducing output in order to raise the market price and thereby earn even higher overall profit on the remaining output. This has the following effects;

- The price-duration curve is higher than in the absence of the market power;

- The market price reaches the price cap more frequently and load shedding occur more frequently than in the absence of market power.

The electricity market in California has shown that a supplier's ability to exercise market power for a time period can damage the intended free competition in the electricity market. The experience with the restructured market has shown that generation suppliers are in a much better position to exercise market power.

There are two ways of exercising market power in electricity markets, (1) Financial withholding and (2) Physical withholding. The financial withholding means bidding excessively above the marginal cost of a generating unit in order to raise the electricity market price above the competitive levels.

The physical withholding means that a generator bids a part of its capacity into the market to reduce the available supply in the market and drive up the market price, [3].

The consequences of exercising market power are (1) profit, (2) wealth transfer, and (3) dead-weight loss. The profit as the first consequence is not only for the exerciser of the market power but it is for all suppliers. In fact, because of the high cost of exercising market power, the market power may become more profitable for those suppliers who do not exercise it.

The wealth transfer from consumers to suppliers is another consequence of exercising market power.

The dead-weight loss is the inefficiency resulting from monopoly power.

Many factors can cause market power in the system. Dominant generators can dictate market price through economic withholding or physical withholding. Transmission system is another factor which may cause market power exercising in the electricity market.

Flaws in the market design may lead to the exercise of market power by suppliers.

Market power problems in liberalised electricity markets are more complicated than those in other markets. This is because electricity can not be stored in a large amount and therefore must be consumed when it is produced.

Market power issues are explained in [5]-[12]. Measurement and assessment of market power in liberalised electricity markets are explained in [13], [14], and [15]. References [16], [17], and [18] deal with diagnosing market power and market power simulation.

From the literature, three different approaches can be realised for modelling market power:

- Market concentration analysis,

- Benchmark price and actual market price,

- Oligopoly equilibrium analysis, [19].

In this paper, we develop the notion of "Stackelberg-Worst Nash equilibrium" for market power modelling. The mathematical structure for calculating the Stackelberg-Worst 
Nash equilibrium is derived. Based on the concept of Stackelberg-Worst Nash equilibrium, the Nodal Market Power index, NMP index, is introduced. The NMP index is a locationally differentiated index to model market power in the system. To visualise market power, a colour contour map is used. The colour contour map is made through a colour spectrum from dark blue to dark red which is assigned to range of NMP indices in the system.

Section II of this paper deals with the mathematical formulation of the NMP index. In section III, the colour contour map is explained. Section IV implements the NMP index and the visualising process using the modified Garver's example system. Section V concludes the paper.

\section{THE MATHEMATICAL MODELLING OF THE WORST NASH EQUILIBRIUM AND THE NODAL MARKET POWER INDEX}

The graph of a marginal cost of a typical generating unit is illustrated in Fig. 1.

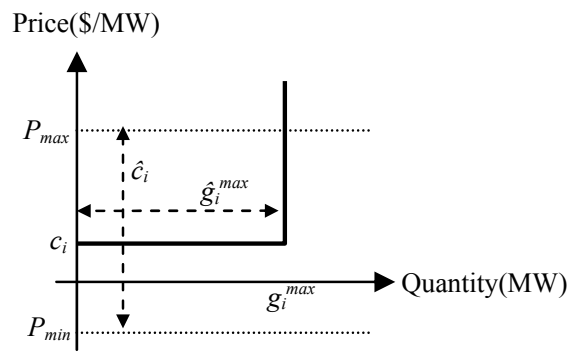

Fig. 1 Stylised representation of the marginal cost of a generating unit

In Fig. $1, c_{i}(\$ / M W)$, and $g_{i}^{\max }(M W)$ are the variable cost, and the generating capacity of the generating unit $i .\left(\hat{c}_{i}, \hat{g}_{i}^{\max }\right)$ is the price-quantity pair offered by the owner of generating unit $i$ to the EMO. $P_{\min }(\$ / M W)$ and $P_{\max }(\$ / M W)$ are the minimum and maximum limits on $\hat{c}_{i}$. These limits are usually set by the electricity market regulator. GenCo $r$ has two decision variables to maximise its profit. These variables are, offered price and offered quantity to the EMO for each generating unit owned by GenCo $r$. The mathematical structures set out in (1) and (2) model the profit maximisation problem of the GenCo $r$ using bilevel programming. Given a set of strategies of all the other generators (that is, an offered price, and offered capacity availability, for each generating unit in each other GenCo's portfolio), the best response for GenCo $r$ is to choose an offered price, and offered capacity availability for each generating unit in GenCo $r$ 's portfolio which satisfies (2):

$$
\begin{aligned}
& \operatorname{Min}_{g_{k}, d_{k}, \theta_{k}, f_{i j}}\left[\sum_{k \in G} \hat{c}_{k} g_{k}+\sum_{k \in D} \operatorname{VoLL}_{k}\left(d_{k}^{\max }-d_{k}\right)\right] \\
& \text { s.t. } \\
& B \theta=g-d \leftrightarrow v \\
& f_{i j}-\gamma_{i j}\left(n_{i j}^{0}+n_{i j}\right)\left(\theta_{i}-\theta_{j}\right)=0 \quad \forall(i, j) \in L \\
& \left|f_{i j}\right| \leq\left(n_{i j}^{0}+n_{i j}\right) f_{i j}^{\max } \quad \forall(i, j) \in L \leftrightarrow u_{1} \\
& 0 \leq g_{k} \leq \hat{g}_{k}{ }^{\max } \quad \forall k \in G \leftrightarrow u_{2} \\
& 0 \leq d_{k} \leq d_{k}{ }_{\max } \quad \forall k \in D \leftrightarrow u_{3}
\end{aligned}
$$

$$
\begin{aligned}
& \operatorname{Max}_{\hat{c}_{i}, \hat{g}_{i}{ }^{\max }} \Pi_{r}=\sum_{i=1}^{n_{G}^{r}}\left\{\sigma\left(v_{i}-c_{i}\right) g_{i}\right\} \\
& \text { s.t. } \\
& P_{\min } \leq \hat{c}_{i} \leq P_{\max } \\
& 0 \leq \hat{g}_{i}^{\max } \leq g_{i}^{\max }
\end{aligned}
$$

(1)

The optimisation problem in (1) is a bid-based, securityconstrained, economic dispatch. The economic dispatch results are calculated per modelled scenario of the system and factor $\sigma$ is the expected number of these scenarios in the horizon year of planning. Optimisation problem (1) is a convex and linear programming problem on its own variables, $g, d, \theta$, and $f_{i j}$.

Using the Karush-Kuhn-Tucker optimality conditions, the optimisation problem (1) can be written as a set of linear and nonlinear equations. Consequently, the structure (2) can be generalised as a classic nonlinear programming problem of the form (3).

$$
\operatorname{Max}_{y \in Y} f_{r}(x, y)
$$

Where in (3), $\boldsymbol{y}$ is the set of all decision variables in (2), $\boldsymbol{Y}$ is the feasible set of decision variables, and $f_{r}$ is the GenCo $r$ profit function. We use the (3) notation to formulate the Nash equilibrium as an optimisation problem.

The Nash equilibrium outcome of the strategic interaction of the GenCos depends on the nature of the strategies allowed to the generating units. There are two conventional approaches to modelling these strategies, [3], [19]:

The Bertrand or Price Game: In this model, each GenCo offers a price for its product which maximises its overall profit, assuming that each other GenCos holds their own offer price fixed. The only decision variable for the GenCo is the offered price of its product. The offered quantity is assumed fixed at the GenCo's true generating capacity.

The Quantity or Cournot Game: In the Cournot model each GenCo chooses to offer a quantity to the market which maximises its profit, assuming that the other GenCos hold their output quantities fixed. The offered price is set at a fixed value, usually the true marginal cost.

The Price and Quantity Game: In a typical liberalised electricity market, GenCos are able to select both the price and quantity which they offer to the market. To an extent, neither the Bertrand nor the Cournot games are able to fully reflect the full set of strategies available to a generator in a typical market. Fig. 2 shows the strategy plane of a GenCo for its generating unit. 


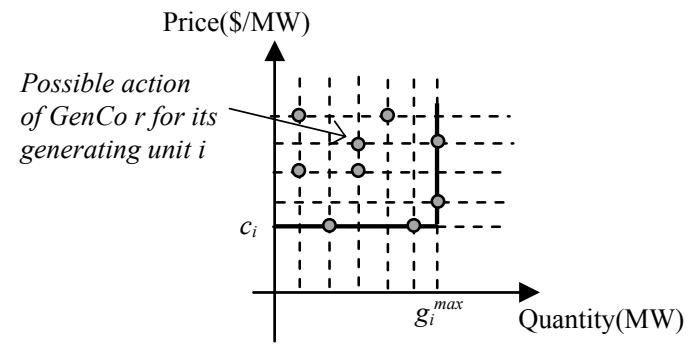

Fig. 3 The strategy plane of GenCo $r$ for its generating unit $i$

The Nash equilibrium problem can be formulated as the problem of finding the zeros of a function $M$, [20].

The set of Nash equilibria of the price-quantity game among GenCos can be expressed as follows:

$$
\begin{aligned}
Y^{*}(x) & =\operatorname{Min}_{y \in Y} M(x, y) \\
& =\operatorname{Min}_{y \in Y} \sum_{r=1}^{N_{G}}\left[\max _{y_{r}^{\prime} \in Y_{r}} f_{r}\left(x, y_{r}^{\prime}, y_{-r}\right)-f_{r}\left(x, y_{r}, y_{-r}\right)\right]
\end{aligned}
$$

We can conclude that the mathematical structure in (5) can calculate all Nash equilibria of the price-quantity game among the GenCos.

$$
\begin{aligned}
& \operatorname{Min}_{c_{i}, \hat{g}_{i} \max }\left\{\sum_{r=1}^{N_{G}}\left[\operatorname{Max}_{x \in X} f_{r}(y)-\sum_{i=1}^{n_{G}^{r}}\left\{\sigma\left(v_{i}-c_{i}\right) g_{i}\right\}\right]\right\} \\
& \text { s.t. } \\
& P_{\min } \leq \hat{c}_{i} \leq P_{\max } \\
& \quad 0 \leq \hat{g}_{i}^{\max _{\max }} \leq g_{i}^{\max }
\end{aligned}
$$

(4)

There are three possible outcomes for the game among GenCos:

The game among GenCos has no equilibrium in pure strategies: In this case, the analytical methods are not able to model the strategic behaviours of GenCos. This paper assumes this case does not arise in practice.

The game among GenCos has only one equilibrium: The unique equilibrium of the game can be found and used to model the strategic behaviours of GenCos.

The game among GenCos has multiple equilibria: This case poses a problem. How should these multiple equilibria be handled?

The problem of multiple equilibria is handled using the concept of the Stackelberg-Worst Nash Equilibrium introduced in [20]. The mathematical structure of the Stackelberg-Worst Nash Equilibrium is introduced in (6).

$$
\operatorname{Max}_{\hat{c}_{k}, \hat{g}_{k} \max }\left\{\sum_{k \in G} c_{k} g_{k}+\sum_{k \in D} \operatorname{VoLL} L_{k}\left(d_{k}^{\max }-d_{k}\right)\right\}
$$

s.t.

The Nodal Market Power index, NMP index, is defined as in (7).

$$
\begin{aligned}
& N M P_{t}=\left[\sum_{k \in G_{t}} c_{k} g_{k}+\sum_{k \in D_{t}} V o L L_{k}\left(d_{k}^{\max }-d_{k}\right)\right]_{\text {Strategic_market }}- \\
& {\left[\sum_{k \in G_{t}} c_{k} g_{k}+\sum_{k \in D_{t}} V o L L_{k}\left(d_{k}^{\max }-d_{k}\right)\right]_{\text {Competitie_market }}}
\end{aligned}
$$

Where in (7), $N M P_{t}$ is the nodal market power index for node $t, G_{t}$ is the set of generators, and $D_{t}$ is the set of loads connected to node $t$.

\section{THE MARKET POWER VISUALIZING USING THE COLOUR CONTOUR MAP}

The NMP index is a locationally differentiated metric for market power cost in the system. The NMP index calculates the contribution of each node of system in total market power cost. Like node voltage, active and reactive power, a colour contour map can be used to visualise the NMP index.

To create the colour-mapping, values of the NMP index were mapped to one of potentially 16.7 million different colours on computer monitor. This corresponds to a value of between 0 and 255 for red, green, and blue. Figure 4 shows a common method for doing this.

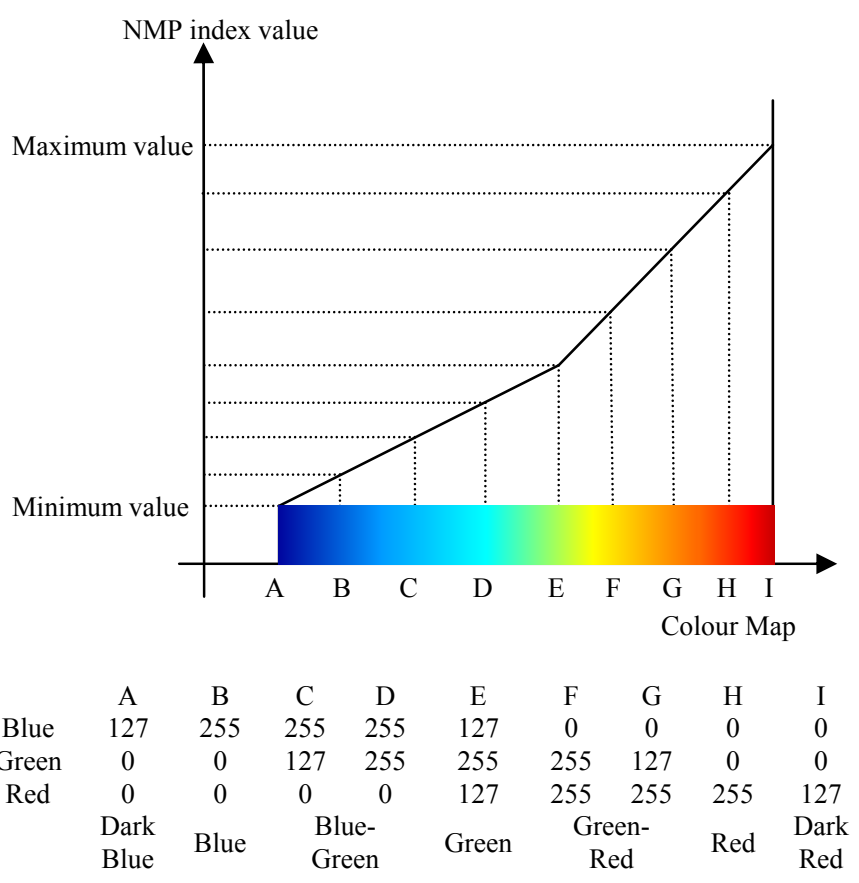

Fig. 4 Colour-mapping for Red $=$ High, Blue $=$ Low 
All values below some minimum value are mapped to dark blue and all values above some maximum value are mapped to dark red.

Using the above mapping curve, a colour contour map for visualising market power in the system can be plotted.

This colour contour map can visualise the exercise of market power in the system. It also can be used for evaluating the impact of different policies on reducing market power in the system.

In section IV, we use the modified Garver's example system to assess the proposed methodology for visualising market power in the system.

\section{Modified Garver's SiX-Bus Example System}

The key parameters of the system are presented in Tables I through III.

TABLE I GENERATORS 'DATA

\begin{tabular}{c|c|c}
\hline Generator & $\mathrm{g}^{\max }(\mathrm{MW})$ & $\mathrm{c}(\$ / \mathrm{MW})$ \\
\hline GenCo1 & 220 & 12 \\
\hline GenCo2 & 460 & 20 \\
\hline GenCo3 & 600 & 35 \\
\hline Total & 1280 & \\
\hline
\end{tabular}

\begin{tabular}{c|c|c}
\multicolumn{3}{|c}{ TABLE II RETAILERS 'DATA } \\
\hline Retailer & $\mathrm{d}^{\max }(\mathrm{MW})$ & VoLL $(\$ / \mathrm{MW})$ \\
\hline R1 & 80 & 20,000 \\
\hline R2 & 130 & 40,000 \\
\hline R3 & 40 & 10,000 \\
\hline R4 & 160 & 30,000 \\
\hline R5 & 115 & 50,000 \\
\hline Total & 525 & \\
\hline
\end{tabular}

TABLE III TRANSMISSION NETWORK DATA

\begin{tabular}{c|c|c|c|c}
\hline Line\# & From & To & Reactance $($ Ohm) & Limit(MW) \\
\hline 1 & Bus1 & Bus2 & 0.004 & 40 \\
\hline 2 & Bus1 & Bus4 & 0.006 & 50 \\
\hline 3 & Bus1 & Bus5 & 0.002 & 60 \\
\hline 4 & Bus2 & Bus3 & 0.002 & 180 \\
\hline 5 & Bus2 & Bus4 & 0.004 & 50 \\
\hline 6 & Bus2 & Bus6 & 0.003 & 40 \\
\hline 7 & Bus3 & Bus5 & 0.002 & 160 \\
\hline 8 & Bus4 & Bus6 & 0.003 & 100 \\
\hline
\end{tabular}

The single line diagram of the example system is shown in Fig. 5. The competitive equilibrium results have been tabulated in Tables IV through V.

The strategy plane of each GenCo consists of 10 actions. In each action, the price bid is set at marginal cost and the quantity bid varies from $10 \%$ to total generation capacity in steps of $10 \%$.

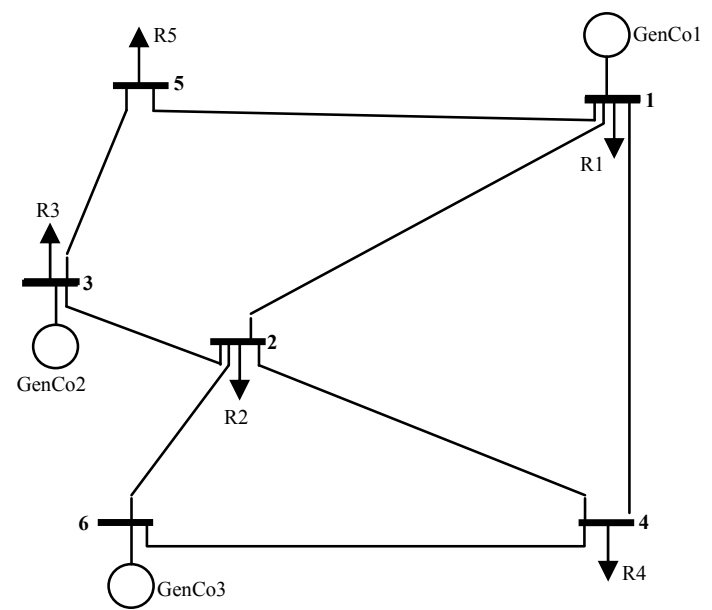

Fig. 5, The modified Garver's example system

TABLE IV ECONOMIC DISPATCH RESULTS UNDER COMPETITIVE EQUILIBRIUM CONDITION

\begin{tabular}{|c|c|c|c|c|}
\hline Bus No. & $\begin{array}{l}\text { Voltage Angle } \\
\text { (degree) }\end{array}$ & $\begin{array}{c}\text { Generation } \\
\text { (MW) }\end{array}$ & $\begin{array}{l}\text { Load } \\
(\mathrm{MW})\end{array}$ & $\begin{array}{l}\mathrm{CLP}^{*} \\
(\$ / \mathrm{MW})\end{array}$ \\
\hline 1 & 0.00 & 156.67 & 80.00 & 12.00 \\
\hline 2 & -5.73 & - & 130.00 & 24.00 \\
\hline 3 & 12.80 & 315.00 & 40.00 & 20.00 \\
\hline 4 & -17.19 & - & 160.00 & 46.00 \\
\hline 5 & -0.19 & - & 115.00 & 16.00 \\
\hline 6 & -6.88 & 53.33 & - & 35.00 \\
\hline \multicolumn{2}{|c|}{ Total/Installed } & $525 / 1280$ & $525 / 525$ & \\
\hline \multicolumn{2}{|c|}{ Average of Nodal Prices(\$/MW) } & \multicolumn{3}{|c|}{25.50} \\
\hline \multicolumn{2}{|c|}{ Total Generation Cost $(\$)$} & \multicolumn{3}{|c|}{10046.67} \\
\hline \multicolumn{2}{|c|}{ Total Value of Lost Load(\$) } & \multicolumn{3}{|c|}{0.0} \\
\hline \multicolumn{5}{|c|}{ CLP $^{*}$ : Competitive Locational Price } \\
\hline
\end{tabular}

TABLE V ECONOMIC DISPATCH RESULTS UNDER COMPETITIVE EQUILIBRIUM

\begin{tabular}{c|c|c}
\multicolumn{3}{|c}{ CONDITION } \\
\hline From & To & Power Flow(MW) \\
\hline Bus1 & Bus2 & 25.00 \\
\hline Bus1 & Bus4 & 50.00 (congested) \\
\hline Bus1 & Bus5 & 1.67 \\
\hline Bus2 & Bus3 & -161.67 \\
\hline Bus2 & Bus4 & 50.00 (congested) \\
\hline Bus2 & Bus6 & 6.67 \\
\hline Bus3 & Bus5 & 113.33 \\
\hline Bus4 & Bus6 & -60.00 \\
\hline
\end{tabular}

TABLE VI THE PRICE-QUANTITY OUTCOMES OF GENCOS 1, 2, 3 FOUND BASED ON THE WORST NASH EQUILIBRIUM

\begin{tabular}{c|c}
\hline & Original Network \\
\hline GenCo 1 $(\$ / \mathrm{MW}, \mathrm{MW})$ & $(12,220)$ \\
\hline GenCo 2 $(\$ / \mathrm{MW}, \mathrm{MW})$ & $(20,92)$ \\
\hline GenCo 3 $(\$ / \mathrm{MW}, \mathrm{MW})$ & $(35,120)$ \\
\hline \hline Total offered capacity $(\mathrm{MW})$ & 432 \\
\hline Total withheld capacity $(\mathrm{MW})$ & 848 \\
\hline \hline Total Generation Cost $(\$)$ & 8,680 \\
\hline Total Value of Lost Load $(\$)$ & $2,543,333$ \\
\hline Total Social Cost $(\$)$ & $2,552,013$ \\
\hline TNSP Cost $(\$) \sigma=10.0$ & $25,520,130$ \\
\hline
\end{tabular}

The Nodal Market Power index, NMP index, for each bus is calculated in Table VII. 


\begin{tabular}{|c|c|c|c|}
\hline \multirow{2}{*}{ Node name } & \multicolumn{2}{|c|}{ Stackelberg-Worst Nash Equilibrium } & \multirow{2}{*}{$\begin{array}{c}\text { The NMP } \\
\text { index (\$) }\end{array}$} \\
\begin{tabular}{c|c} 
Social Cost in \\
Competitive \\
Market (\$)
\end{tabular} & $\begin{array}{c}\text { Social Cost in } \\
\text { Strategic } \\
\text { Market (\$) }\end{array}$ & \\
\hline Bus1 & 1,880 & 136,040 & $+134,160$ \\
\hline Bus2 & 0.0 & 960,000 & $+960,000$ \\
\hline Bus3 & 6,300 & 401,840 & $+395,540$ \\
\hline Bus4 & 0.0 & 99,900 & $+99,900$ \\
\hline Bus5 & 0.0 & 950,000 & $+950,000$ \\
\hline Bus6 & 1,866 & 4,200 & $+2,334$ \\
\hline
\end{tabular}

Fig. 6 shows the colour contour map of the Modified Garver's example system. Dark red in the contour map represents high market power in the system and dark blue shows the low market power measured using the NMP index.

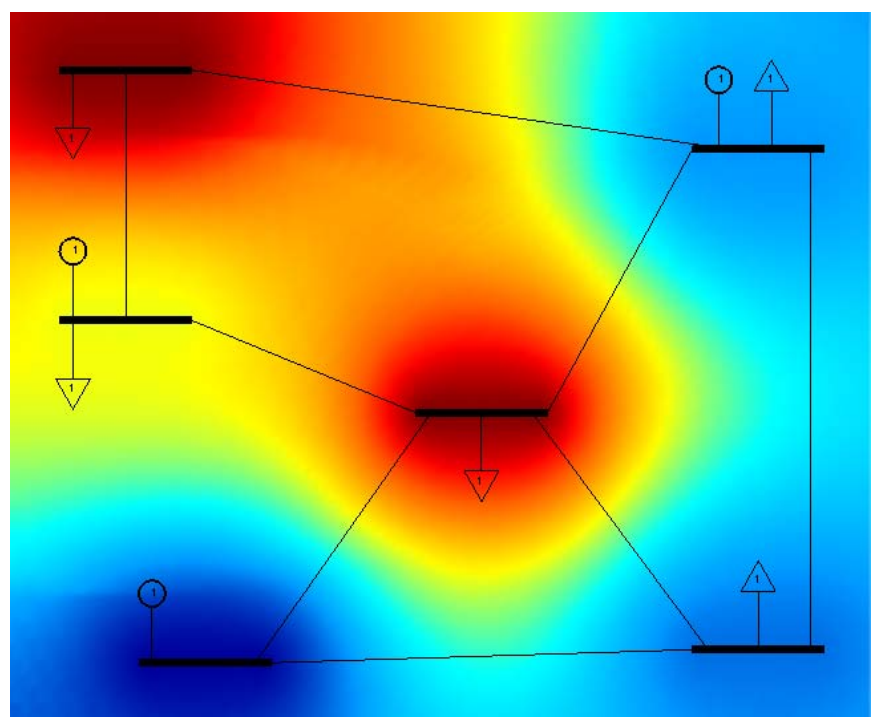

Fig. 6, The colour contour map for visualising market power in the modified Garver's example system

\section{CONCLUDING REMARKS}

This paper deals with a mathematical structure for modelling market power in liberalised electricity markets. The mathematical structure is based on the concept of StackelbergWorst Nash equilibrium. The Nodal Market Power index, NMP index, is defined as a locationally differentiated metric for market power modelling. Using the NMP index, a colour contour map is designed to visualise market power. In the colour contour map, the dark red represents the node which has the highest value of NMP index and the dark blue represents the node with the lowest NMP index. The proposed approach for modelling and visualising market power can be used for analysing the impact of different electricity market policies on market power.

\section{REFERENCES}

[1] S. Stoft, Power System Economics, Designing Markets for Electricity, IEEE press, 2002

[2] D. Biggar, Economic Analysis of Power Systems, Australian Competition and Consumer Commission.

[3] A. F. Rahimi, and A. Y. Sheffrin, "Effective market monitoring in deregulated electricity market," IEEE Trans. Power Systems, vol. 18, pp. 486-493, May 2003.
[4] T. Li, M. Shahidehpour, "Market power analysis in electricity markets using supply function model", IMA Journal of Management Mathematics, pp. 339-354, vol. 15, 2004.

[5] S. Stoff, Power Systems Economics: Designing Markets for Power. New York: IEEE/Wiley, 2002.

[6] M. Shahidehpour and M. Alomoush, Restructured Electrical Power Systems: Operation, Trading, and Volatility. New York: Marcel Dekker, 2001.

[7] F. L. Alvarado, "Market power: A dynamic definition," in Proc. Conf. Bulk Power Systems Dynamics and Control, Santorini, Greece, Aug. 1998.

[8] A. A. Foer, "Institutional contexts of market power in the electricity industry," Electricity J., vol. 12, no. 4, pp. 13-20, May 1999.

[9] K. W. Costello and K. Rose, "Some fundamental questions on market power: No easy answers for state utility regulators," Electricity J., vol. 11 , no. 6, pp. 71-79, July 1998.

[10] A. K. David and F. Wen, "Market power in electricity supply," IEEE Trans. Energy Conversion, vol. 16, pp. 352-360, Dec. 2001.

[11] J. Tirole, The Theory of Industrial Organization. Cambridge, MA: MIT, 1988.

[12] W. M. Landes and R. A. Posner, "Market Power in Antitrust Cases," Harvard Law Review, vol. 94, no. 5, pp. 937-996, 1981.

[13] G. Gutierrez, M. Madrigal, F. Rosenzweig, and J. Aguado, "The effect of bilateral contracting and demand responsiveness in market power in the mexican electricity system," in Proc. IEEE Power Tech 2003 Conf., Bologna, Italy, June 2003.

[14] P. Visudhiphan and M. D. Ilic, "Dependence of generation market power on the demand/supply ratio: Analysis and modeling," in Power Engineering Society Winter Meeting, vol. 2, Singapore, Jan. 2000, pp. $1115-1122$.

[15] D. Gan and D.V. Bourcier, "Locational market power screening and congestion management: Experience and suggestions," IEEE Trans. Power Syst., vol. 17, pp. 180-185, Feb. 2002.

[16] S. Borenstein, J. B. Bushnell, and F. Wolak, "Diagnosing market power in California's deregulated wholesale electricity market," in POWER Working Paper 064, 1999, Univ. California Energy Inst.

[17] J. Bushnell and C. Saravia, "An empirical evaluation of the competitiveness of the new england electricity market," in CSEM Working Paper 101, May 2002, Univ. California Energy Inst.

[18] S. M. Harvey and W. H. Hogan, "Market power and market simulations," in Working Paper, July 2002, John F. Kennedy School of Government

[19] C. Day, B. Hobbs, and J. Pang, "Oligopolistic competition in power networks: a conjectured supply function approach," IEEE Transactions on Power Systems, Vol. 17, pp. 597-607, August 2002.

[20] M. R. Hesamzadeh, D. Biggar, N. Hosseinzadeh, P. J. Wolfs, "Derivation of A Mathematical Structure for Market-Based Transmission Augmentation in Oligopoly Electricity Markets using Multilevel Programming", IEEE Power Engineering Society General Meeting, Calgary, Alberta, Canada, 26-30 July 2009

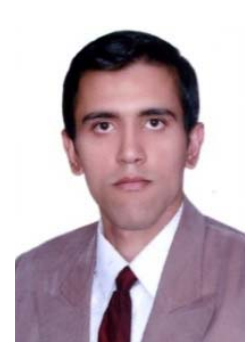

Mohammad Reza Hesamzadeh (B.Sc.EE, M.Sc.EE, IEEE-GSM'08) is a $\mathrm{PhD}$ student at Swinburne University of Technology, Melbourne, Australia. His special fields of interest include power system economics, high voltage transmission system planning and design, and electricity market analysis. He was the Vice-Chair of IEEE Queensland, Power and Energy Chapter, in 2008. He is a Graduate Student Member of IEEE, and a Member of the Computer and Analytical Methods Subcommittee (CAMS) of the Power System Analysis, Computing, and Economics (PSACE) Committee of the IEEE. He is a Professional Engineer in Australia.

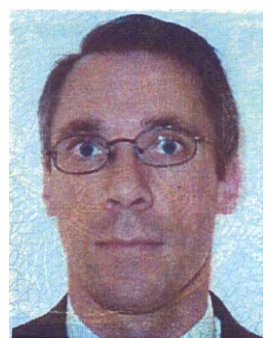

Darryl Ross Biggar is an economist with the Australian Competition and Consumer Commission and the Australian Energy Regulator. He specializes in the economics of regulation, including issues such as the design of incentive mechanisms, foundations of regulation, and the design of electricity markets and water markets. He has a particular interest in electricity markets including issues of nodal and 
zonal pricing and the measurement and control of market power.

Prior to the ACCC, he worked for the OECD in Paris, the New Zealand government, and for University College, London. Biggar has a $\mathrm{PhD}$ in economics from Stanford University and an MA in Mathematics from Cambridge University. He is a native of New Zealand.

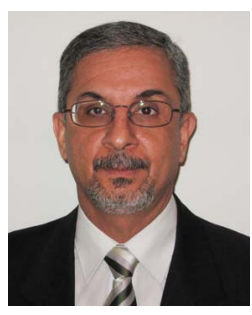

Nasser Hosseinzadeh (IEEE-M'86, CIGRE-APC1) is currently with Swinburne University of Technology, Melbourne. Earlier, he worked as a senior lecturer at Central Queensland University in Australia, as a lecturer at Monash University Malaysia and as an assistant professor at Shiraz University, Iran.

His special fields of interest include power system analysis and planning, applications of intelligent control in power engineering, power system stability, wind energy systems, and engineering education. Dr. Hosseinzadeh is a registered member of Engineers Australia, a member of IEEE and also is on the Australian Panel AP C1, System Development and Economics, of CIGRE.

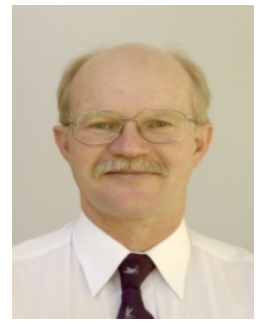

Peter Joseph Wolfs (IEEE-M'80-SM'99) was born in Rockhampton Australia in 1959. He graduated from the Capricornia Institute of Advanced Education in 1980 with a B.Eng. degree. He subsequently obtained the M.Eng. degree from the Philips International Institute in the Netherlands in 1981 and the Ph.D. degree at the University of Queensland in 1992. He is the Western Power Chair of Power Engineering at the Department of Electrical and Computer Engineering at Curtin University Australia. His special fields of interest include smart grids, distributed generation, power quality and harmonics, rural power supply, photovoltaic systems, power electronics, and railway traction power supply. Professor Wolfs is a Fellow of Engineers Australia, a Registered Professional Engineer in the State of Queensland and a member of the Railway Technical Society of Australia. 